\title{
NOTAS PROVISÓRIAS SOBRE A NOÇÃO DE SOCIALIZAÇÃO: UMA LEITURA EM PERIÓDICOS DA EDUCAÇÃO (1998-2018)
}

\author{
Maria da Graça Jacintho Setton ${ }^{1}$ \\ Adriana BozzetTo ${ }^{2}$
}

\begin{abstract}
RESUMO: Os objetivos deste artigo foram identificar e analisar o uso do conceito socialização em artigos publicados em revistas avaliadas como A1, no campo da educação, entre os anos de 1998 e 2018. Partindo do pressuposto de que as teorias da socialização não são apropriadas em um consenso teórico único, a intenção é conhecer as formas pelas quais elas têm sido incorporadas por pesquisadores, a fim de problematizar as fragilidades e/ou o potencial analítico da noção. Por meio de consulta em periódicos indexados na base Scientific Electronic Library Online (SciELO), uma das mais importantes bases de dados de publicações científicas, foi possível classificar 87 artigos tendo como base a palavra-chave socialização. Para desenvolver o argumento, dividiu-se este material em seis categorias: socialização em tempos contemporâneos; socialização e aportes teóricos; socialização: família/escola; infância e socialização de gênero; socialização profissional; e socialização política. Foi possível verificar usos múltiplos do conceito, abarcando maneiras genéricas e pontuais do termo, usos com breves apontamentos definidores e, até mesmo, modos circunstanciados na tentativa de avançar e/ou recuperar seu vigor conceitual nas pesquisas no campo da educação.
\end{abstract}

Palavras-chave: Socialização. Processos de socialização. Processos educativos. Sociologia da educação.

\section{PROVISIONAL NOTES ON THE NOTION OF SOCIALIZATION: A READING IN EDUCATION PERIODICALS (1998-2018)}

\begin{abstract}
The objective of this article is to identify and analyze the use of the concept of socialization in articles published in journals evaluated as A1, in the field of Education, between 1998 and 2018. Assuming that socialization theories are not appropriate from a single theoretical consensus, the intention is to know the ways in which they have been incorporated by researchers in order to problematize the fragilities and/or analytical potential of the notion. From a consultation in
\end{abstract}

1.Universidade de São Paulo, Faculdade de Educação - São Paulo (SP), Brasil. E-mail: gracaset@usp.br

2.Universidade Federal do Pampa - Bagé (RS), Brasil. E-mail: adrianabozzetto@unipampa.edu.br

Este artigo é resultado da pesquisa de pós-doutorado (2018-2019) de Adriana Bozzetto intitulada Um levantamento do conceito de socialização em periódicos das áreas de Educação e Educação Musical de 1990 a 2018, sob supervisão de Maria da Graça Jacintho Setton, pela Faculdade de Educação da Universidade de São Paulo. 
journals indexed in the SciELO database, it was possible to classify 87 articles based on the keyword socialization. To develop the argument, this material was divided into six categories: i) socialization in contemporary times; ii) socialization and theoretical contributions; iii) socialization - family/school; iv) childhood and gender socialization; v) professional socialization; and vi) political socialization. It was possible to verify multiple uses of the concept, encompassing generic and punctual forms of the term, uses with brief definitive notes, and even detailed ways in the attempt to advance and/or regain its conceptual vigor in research in the field of education.

Keywords: Socialization. Socialization processes. Educational processes. Sociology of education.

\title{
NOTAS PROVISIONALES SOBRE LA NOCIÓN DE SOCIALIZACIÓN: UNA LECTURA EN PERIÓDICOS DE LA EDUCACIÓN (1998-2018)
}

\begin{abstract}
RESUMEN: El objetivo de este artículo es identificar y analizar el uso del concepto de socialización en artículos publicados en revistas evaluadas como A1, en el campo de la educación, entre 1998 y 2018. Suponiendo que las teorías de la socialización no son apropiadas basadas en un solo consenso teórico, la intención es conocer las formas en que los investigadores los han incorporado para problematizar las fragilidades y/o el potencial analítico de la noción. Desde una consulta en revistas indexadas en la base de datos SciELO, fue posible clasificar 87 artículos basados en la palabra clave socialización. Para desarrollar el argumento, este material se dividió en seis categorías: i) socialización en los tiempos contemporáneos; ii) socialización y aportes teóricos; iii) socialización - familia/escuela; iv) infancia y socialización de género; v) socialización profesional; y vi) socialización política. Fue posible verificar múltiples usos del concepto, abarcando formas genéricas y puntuales del término, usos con breves notas definitivas, e incluso formas detalladas en el intento de avanzar y/o recuperar su vigor conceptual en la investigación en el campo de la educación.
\end{abstract}

Palabras-clave: Socialización. Procesos de socialización. Procesos educativos. Sociología de la educación.

\section{Introdução}

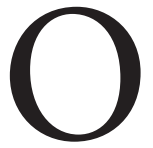

s objetivos destes apontamentos são identificar e analisar estudos que fizeram uso do conceito socialização nos últimos 20 anos, a fim de compreender sua apropriação em pesquisas no campo da educação. Trata-se de uma tentativa de problematizar o potencial analítico de uma noção clássica no interior das ciências sociais, notadamente na área da sociologia da educação e da cultura. Concordando com Berthelot (1983), o conceito socialização compreende um conjunto de investigações que possuem foco nas instituições, nos valores, na história e na vida dos indivíduos. Ou seja, um conceito capaz de associar, em uma mesma perspectiva, quatro elementos essenciais para a análise de qualquer fenômeno social. Dessa maneira, tal conceito, ainda que não perceptível a todos, possui potencial analítico ímpar, na 
medida em que serve para interpretar aspectos da reprodução social, a origem social dos grupos e suas representações em várias dimensões socioculturais.

Ademais, a noção de socialização é um operador analítico que dá conta da produção, difusão e reprodução, permitindo observar a gênese das formas de compreender o mundo, os habitus individuais e grupais. A noção de socialização também aborda as relações indissociáveis entre indivíduo e estrutura social, aproximando-se dos processos de individualização e construção identitária. Informando sobre a constituição da estrutura social, a noção permite, ainda, desvelar os mecanismos de resistência e disputa entre interesses sociais, suas dinâmicas internas e/ou possíveis transformações. Desta feita, trata-se do entendimento da noção de socialização em uma perspectiva dialógica e multidimensional. Mais precisamente, seguindo os ensinamentos de Guy Vincent (1988), apoiando-se em Georg Simmel (1917), se deveriam compreender os processos socializadores como oportunidades contínuas de fazer-se e refazer-se enquanto indivíduo. Portanto, o verbo socializar deveria ser conjugado de forma reflexiva: socializar-se.

Partindo desses pressupostos, realizou-se uma pesquisa, em abril de 2018 ${ }^{1}$, na Plataforma Sucupira, Qualis periódicos classificação A1, no quadriênio 2013-2016, da área de educação. A intenção era ter acesso aos estudos que foram avaliados pelos pares e que representavam o que havia sido produzido no campo.

Doze periódicos ${ }^{2}$ fizeram parte deste estudo ${ }^{3}$ : Educação e Sociedade, com 23 artigos; Educação e Pesquisa, com 15 estudos; Cadernos de Pesquisa, com 11 documentos; Revista Brasileira de Educação, com nove trabalhos; Pro-Posições, com oito artigos; Educação \& Realidade, com seis estudos; Cadernos CEDES, com quatro trabalhos; Educação em Revista e Sociologias, ambas com três artigos cada uma; Educar em Revista e Educação, com dois estudos cada uma; e, por fim, a Revista Brasileira de Ciências Sociais, com apenas um artigo $^{4}$, perfazendo o total de 87 documentos 5 .

Para a análise, dividiu-se o material em seis categorias ${ }^{6}$ :

- Socialização em tempos contemporâneos;

- Socialização e aportes teóricos;

- Socialização: família/escola;

- Infância e socialização de gênero;

- Socialização profissional;

- Socialização política.

Embora se possa apresentar certa arbitrariedade na classificação empreendida, a intenção era emparelhar estudos que possuíam foco institucional semelhante, ainda que se identificasse alguma proximidade em suas perspectivas analíticas.

\section{Socialização em tempos contemporâneos}

Os 13 artigos que compõem a categoria socialização em tempos contemporâneos são, na sua maioria, ensaios (oito) em que os autores buscam mapear as novas condições socializadoras iniciadas em meados do século XX. Cinco desses estudos baseiam-se em pesquisas exploratórias que chamam a atenção para aspectos que exemplificam novidades no campo da socialização. É possível afirmar que os artigos dão um panorama sobre preocupações acadêmicas acerca de formas diferenciadas de se socializar. Tangenciando aportes sociológicos e psicológicos, tais estudos revelam a interdisciplinaridade do conceito (HONNETH, 2013; PAIS, 2007; LIMA; FAZZI, 2018; PETITAT, 2011). Aqui se encontram reflexões em que as noções de individualização, identidade, self e subjetividade se correspondem, pois servem para anunciar que os indivíduos contemporâneos estão submetidos a uma nova ordem social que lhes possibilita maior autonomia 
nas escolhas e crescente participação na construção de si (BARRERE; MARTUCCELLI, 2001). Oferecendo maior centralidade dos sujeitos no cerne dos processos sociais nos quais se inserem, os autores enfatizam a emergência de uma nova ambiência relacional entre o(s) eu(s) e o(s) outro(s) significativo(s) (HONNETH, 2013; LIMA; FAZZI, 2018).

As mudanças nas instituições tradicionais da socialização, aqui entendida em seu uso mais corrente, ou seja, instâncias responsáveis pelo processo gradual de internalização de comportamentos sociais reativos (HONNETH, 2013; PETITAT, 2011), fortalecem a ideia de que "a ênfase na autonomia, individuação e reflexividade do sujeito supõe 'algo' de permanente num sujeito que é plural e cuja identidade nunca é fixa” (LIMA; FAZZI, 2018, p. 264). A diversidade de contextos socializadores para além dos muros escolares, tais como as mídias, suas expressões musicais e de entretenimento (DAYRELL, 2002; FONTENELLE, 2002) ou tecnológicas (PRAZERES, 2015; TEDESCO, 2002), anuncia a necessidade de se repensar a escola, hoje incapaz de imprimir nos indivíduos valores éticos e morais que associem necessidades individuais e coletivas, uma instituição provida de trunfos socializadores reconhecidos até então como legítimos, os quais a considera como autoridade e como promotora da igualdade social (BARRERE; MARTUCCELLI, 2001; CHAVES, 2015).

Se nas escolas os alunos aprendiam os usos e costumes de sua sociedade tornando-se membros de uma comunidade ou nação, aderindo continuamente a um conjunto de valores, atualmente uma educação/ socialização difusa se encontra presente, promovendo interações, socializando no sentido de se colocar em conexão, de entrar em interação ou familiarização com um universo relacional amplo e diversificado (PETITAT, 2011). Tendo como base os estudos clássicos sobre socialização (Vergesellschaftung) de Georg Simmel, André Petitat (2011) avança em uma leitura mais complexa do termo, associando-o ao processo de individualização, tal como Norbert Elias e Pierre Bourdieu (SETTON, 2018).

Os estudos mencionados não se servem de definições fechadas acerca dos processos de socialização, pois apontam para novos ambientes socializadores e para a capacidade dialógica de os sujeitos interagirem e negociarem referências em seus contextos plurais. Contudo, parte deles (LOPES, 2009; DIAS DA SILVA; PEREIRA, 2013; VELOSO et al., 2018; CHAVES, 2015) apropria-se do conceito tendo como alusão a obra de Émile Durkheim (1978), sociólogo que imprimiu na sociologia francesa e grande parte na sociologia brasileira uma versão unilateral e homogênea do processo de incorporação de normas sociais.

\section{Socialização e aportes teóricos}

O conjunto de artigos relativos ao eixo socialização e aportes teóricos é constituído de 13 ensaios e um relato de pesquisa (ABRANTES, 2014). Trata-se da tentativa de autores nacionais e estrangeiros de se aprofundar na discussão acerca dos processos de socialização. O maior expoente desse grupo é Bernard Lahire 7 , com dois artigos publicados na revista Educação e Pesquisa, da Faculdade de Educação da Universidade de São Paulo (FE-USP), nos anos de 2008 e 2015. Com vasta produção na área, Lahire preocupa-se em trazer um programa de estudos detalhado nesses artigos, no campo da socialização (LAHIRE, 2015) e no da sociologia psicológica (LAHIRE, 2008). Em ambos têm-se um caráter metodológico que procuram circunscrever os campos de investigação aos quais o autor tem se dedicado. Lahire tem a faculdade de ser didático e atrativo. Traz um conjunto de afirmações epistemológicas que organizam a realização de pesquisas no campo da socialização não só em seu caráter institucional, mas também individual. Não deixa de relacionar seus incentivos com uma crítica ao que já foi realizado sobre o processo de aquisição de disposições de cultura. Para ele, uma pesquisa a respeito dos processos socializadores, "para ter uma verdadeira utilidade sociológica e ser cientificamente um tanto rentável” (LAHIRE, 2015, p. 1395), deveria se ocupar de evidências empíricas, 
contextualizadas em espaços-tempos institucionais e em estratégias educativas capazes de inculcar disposições variadas. Trata-se de leituras obrigatórias para quem tem interesse em desenvolver estudos nessa linha.

Três outros artigos também ampliam formas de observar os processos socializadores reportando-se a autores clássicos e mais contemporâneos. Tecendo considerações sobre Georg Simmel, George Mead e Walter Benjamin, Grigorowitschs $(2008 ; 2010)$ instiga o leitor com provocações sobre a pertinência ou não do uso do conceito. A autora busca, nos textos clássicos, evidências no que concerne à necessidade de acrescentar o vocábulo processo no estudo das experiências socializadoras em razão de sua forte vinculação com os mecanismos de sociação com um coletivo. Indivíduo e sociedade, individualização, selfe socialização são termos de uma mesma moeda, aquela que expressa a construção do social. Os textos de Simmel datam do início do século XX, e os textos de Mead e Benjamin são de meados desse mesmo século. De forte tendência à erudição, a autora faz uso de uma farta bibliografia alemã. Tanto ela como Marchi (2009) têm como eixo de investigação a sociologia da infância. Ambas trabalham na direção de criticar uma abordagem adultocêntrica do fenômeno da infância, reforçando preocupações alinhadas a um dos tópicos deste artigo.

Destacam-se, ainda desse grupo, os ensaios de Setton ${ }^{8}$. A autora busca de forma contínua divulgar seus achados teóricos no campo dos processos socializadores. Ao todo, nesses 20 anos, Setton publicou sete ensaios que se enquadram no eixo dos aportes teóricos e mais dois outros alocados nos eixos família e escola (SETTON, 2005) e socialização política (GOMES e SETTON, 2016). Ela desenvolve um plano de trabalho em que apresenta contribuições teóricas sobre as novas condições de socialização (SETTON, 2002), incorporando em suas análises a obra de Pierre Bourdieu (1992; 1998), na perspectiva de discutir os efeitos de uma nova configuração social e a necessidade de reavaliar o conceito de habitus. Aproxima, ainda, autores que acrescentariam nesse debate, como Marcel Mauss e Norbert Elias (SETTON, 2013; 2018). Vale salientar que Setton, ao pensar a realidade brasileira, procura nos ensaios anteriormente relacionados trabalhar com o ponto de vista grupal dos processos de socialização. Contudo, em outros dois artigos, lança o desafio de pensar a socialização por meio de um estudo de caso específico, centrado em um único indivíduo (SETTON, 2011; 2015). É, pois, um conjunto de reflexões que demonstram um visível programa de estudos acerca do tema socialização.

\section{Socialização: família/escola}

O eixo de artigos classificados na categoria socialização: família/escola possui 17 estudos. A maioria (11) revela resultados de pesquisa. Seis deles caracterizam-se como ensaios, na medida em que possuem caráter opinativo acerca das relações família/escola no âmbito dos processos de socialização. É possível dividir esse grupo em dois conjuntos. O primeiro traz reflexões sobre experiências socializadoras no interior da família e da escola, mas não se ocupa em definir o conceito (SILVA, 2002; MOTA, 2004; SIROTA, 2005; TOMIZAKI, 2010; POLLOCK, 2010; WEISS, 2015), e vários oferecem referências autorais nas quais se baseiam ainda que de forma pouco circunstanciada (CAMACHO, 2001; VIANNA, 2005; CURY, 2006; DAYRELL, 2007; MORAIS; NEVES, 2013; QUARESMA, 2015; LEONARDI, 2017).

Ou seja, citando de maneira pontual o processo pelo qual indivíduos interiorizam normas e formas de conduta, parecem compreender tais experiências como práticas realizadas de maneira unilateral, isto é, experiências em que as instituições se esforçam em transmitir formas de ser, agir e pensar sem que se mencione o papel ou a reação dos sujeitos nessa relação. Ainda que não se possa afirmar que os autores de tais estudos não tenham ciência da complexidade dialógica dos processos socializadores, pois se tem apenas um artigo para cada autor, o que se observa é que, focadas em seus objetos de pesquisa, tais como 
juventude, geração, valores derivados das heranças familiares e ensinamentos escolares, entre outros, tais reflexões se concentram em discorrer sobre resultados de investigações. O conceito de socialização é aqui apropriado em uma perspectiva vertical como um processo de compartilhar, transmitir, ensinar, voluntária ou involuntariamente, um conjunto de saberes e práticas que auxiliam a entrada dos indivíduos em universos sociais específicos.

Nesse eixo, o uso do conceito é baseado em uma bibliografia legitimada. Autores como Basil Bernstein, Peter Berger, Thomas Luckmann, François Dubet, Danilo Martuccelli, Bernard Lahire e Maria da Graça Setton são os mais citados. Os estudos revelam leituras atentas, mas não ampliam nem capacitam o leitor a entendimento complexo e multidimensional das realidades sociais. É possível afirmar, ainda, que a exploração do conceito de socialização não proporciona correlações com simultâneas estratégias educativas mais estreitamente relacionadas ao ambiente escolar e instrucional. Tais desenvolvimentos demandam um espaço discursivo maior, em que um artigo muitas vezes não pode ser executado; contudo, vale ressaltar que a maioria dos artigos desse grupo (com exceção de MOTA, 2004; VIANNA, 2005; MORAIS; NEVES, 2013; QUARESMA, 2015) pouco comenta o caráter de interdependência entre as instâncias socializadoras no processo de construção dos indivíduos, chamando atenção a uma única instituição na construção das disposições de habitus dos sujeitos.

O segundo tópico desse grupo, por outro lado, mostra-se bastante diverso. O primeiro estudo, de Jerusa Vieira Gomes (1994), o mais antigo dos artigos encontrados, revela uma surpreendente análise sobre os processos de socialização, pois parece inaugurar uma sequência de estudos que apontam a heterogeneidade, a multiplicidade e a multidimensionalidade das experiências de socialização. Nas palavras da autora, "embora seja ainda inegável a importância da família como grupo socializador, outras agências sociais e até mesmo alguns espaços competem com ela, diuturnamente, e vão se tornando demasiado fortes na sociedade atual” (GOMES, 1994, p. 60)9 .

Outro artigo que segue essa linha de raciocínio, ou seja, a interdependência entre as esferas de socialização, de autoria de Setton (2005), traz uma perspectiva relacional entre as instituições família, escola e mídia na tentativa de explicar o sucesso escolar em meios populares. É um dos primeiros trabalhos na área da sociologia da educação e da cultura que exploram a sinergia do potencial educativo das mídias com o trabalho pedagógico das famílias e da escola (ROMANELLI, 2013).

Dois outros trabalhos ensaísticos, de autoria de Daniel Thin (2006; 2010), ao apresentar dissonâncias entre as lógicas socializadoras das famílias e das escolas, têm a preocupação de referenciar o uso, a bibliografia e o conceitual dos processos socializadores, empreendendo um trabalho didático de fortalecer e sinalizar o potencial heurístico da noção. Tudo leva a crer que tal iniciativa deriva do lugar que esse pesquisador ocupou em um dos maiores e mais legitimados grupos de pesquisa na Europa que trabalha com o conceito de socialização. O Groupe de Recherche sur la Socialisation (GRS), fundado em 1976 na Universidade Lumière Lyon 2, na França, durante 34 anos se ocupou em difundir um aporte analítico substantivo, alimentando pesquisas no mundo inteiro, inclusive no Brasil. Em 2011, o GRS fundiu-se com outros laboratórios de pesquisa para integrar um laboratório único, denominando-se de Centre Max Weber. As referências teóricas de Thin são amplas, das mais tradicionais — Durkheim, Parsons, Elias, Bernstein, Berger e Luckmann —, às de seus colegas de trabalho mais próximos - Guy Vincent e Bernard Lahire.

\section{Infância e socialização de gênero}

O conjunto de artigos infância e socialização de gênero é composto de 17 estudos. A maioria são resultados de pesquisas realizadas no âmbito da pós-graduação brasileira. Três deles são ensaios (PLAISANCE, 
2004; MOLLO-BOUVIER, 2005; ABRAMOWICZ; OLIVEIRA, 2010), e um deles é um levantamento sobre teses e dissertações (CARVALHO, 2012).

Os trabalhos versam, sobretudo, acerca da fase da vida infantil em que se apreendem disposições de cultura, tais como o controle pessoal em relação aos adultos e pares, bem como disposições de gênero, fora e/ou dentro da escola, uma educação implícita realizada por meio de práticas naturalizadas que orientam comportamentos e representações sociais. Por meio de suportes lúdicos (MORIN-MESSABEL et al., 2016) ou mesmo da divisão do trabalho doméstico (SENKEVICS; CARVALHO, 2015), competências motoras, afetivas e cognitivas são desenvolvidas.

Um número bastante expressivo de estudos não se ocupa em definir o que se compreende por socialização, apresentando breves apontamentos genéricos sobre o processo de apreensão de normas de comportamentos na infância, como a disciplina, a docilidade para o aprendizado, ou mesmo modelos de conduta diferenciados por sexo. São estudos que, possuindo um foco específico de pesquisa, utilizam o conceito socialização como sinônimo de educação, atividade social vertical em que não se exploram a negociação nem possíveis resistências ao processo de incorporação de disposições generificadas (AFONSO, 1995; BRITO, 2006; CARVALHO, 2012; CARVALHO et al., 2014) ou masculinas (BANDEIRA, 2010; CHAVES, 2012).

Por outro lado, um grupo destaca-se pela preocupação em desenvolver o poder conceitual de socialização em suas pesquisas, de forma a pensá-lo como ação horizontal, em que se exige a participação do sujeito em seu processo de aprendizagem e de formação identitária (MARTINS FILHO, 2008; MORIN-MESSABEL et al., 2016; SANTOS, 2017). Apropriando-se da noção de processo de socialização, alguns artigos explicitam o caráter interativo, complexo, plural e multidimensional da aquisição e incorporação de normas e valores (BARBOSA, 2007; MÜLLER, 2008; GOMES, 2008; SANTOS, 2017).

Vale salientar que grande parte dos trabalhos dessa categoria, ainda que não explicite, faz uso da relação de sinergia e interdependência entre esferas de socialização. Tomando como locus de investigação as instituições família, creche e escola, demonstra um trabalho de construção de representações simbólicas que tendem a se perpetuar, pois são adquiridas na pequena infância e são consolidadas ao longo de todo um processo educativo.

Desse conjunto de documentos, três trabalhos destacam-se, pois problematizam questões relativas à infância considerando novos aspectos do tema e enfatizando a necessidade de se observar a criança como sujeito de direito, de opinião e produtora de cultura e significados (ABRAMOWICZ; OLIVEIRA, 2010). Como produtora de cultura, a criança é capaz de participar do processo de construção do mundo social. Os artigos chegam a criticar textualmente os antigos entendimentos do processo, bem como alertam para o aspecto não linear, contínuo e interativo dessas experiências (PLAISANCE, 2004; MOLLO-BOUVIER, 2005). Um elemento interpretativo de todos os estudos desse eixo deve ser salientado. Trata-se da necessidade de parte do campo da sociologia da infância de formalizar um entendimento acerca da pequena infância, fugindo de visões adultocêntricas e propondo a leitura em que a criança é um ser, ainda que em formação, mas que já possui capacidade de agir sobre o mundo e interferir em seu próprio processo educativo.

Por último, valeria citar as principais referências utilizadas pelos autores. Além dos mais clássicos no tema, como Émile Durkheim, Peter Berger e Thomas Luckmann, Eric Plaisance, Claude Dubar e Bernard Lahire, destacam-se Sylvie Octobre, Daniel Thin, Maria da Graça Setton, Martha Traverso-Yépez e Véronique Rouyer, pois revelam novos aportes.

\section{Socialização profissional}

O grupo de artigos sobre socialização profissional é constituído de dez estudos. Um deles foi escrito por um dos expoentes do tema, Claude Dubar. Seis deles ocupam-se dos processos de profissionalização 
de docentes, e três tratam da entrada dos jovens no mundo profissional. Dubar, em seu ensaio de 2012, inspirando-se em estudos sobre trajetórias sociais, observa que as experiências socializadoras assumem a força de processos de construção de identidades. Em outras palavras, a profissionalização e/ou a aquisição de competências implica um processo de reconhecimento de si e entre seus pares, reconhecimento este nos âmbitos monetário e identitário.

No caso da socialização profissional docente, é possível observar o diálogo e o consenso bibliográfico acerca do tema. Dubar é a grande referência em estudos empreendidos na Pontifícia Universidade Católica do Rio de Janeiro (PUC-Rio) por Lüdke (1996), Freitas (2002) e Lüdke e Boing (2004). Todos trazem a discussão de que a formação docente, na prática e na teoria, promove identidade profissional. Os aportes teóricos trazidos para análise revelam que esses estudos se preocupam em observar a continuidade de aprendizagens na família e nos cursos profissionalizantes, mas usam uma perspectiva unilateral do processo (GARIGLIO, 2015). Não problematizam as resistências nem os atritos derivados dessa experiência formativa. Apenas sinalizam um sentimento de crise identitária desses profissionais em função do baixo reconhecimento social da docência e do tardio aprendizado das salas de aula (GOMES; PEREIRA, 2009).

Um artigo destaca-se nesse grupo (KNOBLAUCH, 2017). Trata-se da apresentação de resultados parciais de pesquisa entre alunas do curso de Pedagogia, em que se revela a preocupação de analisar as relações de interdependência entre as esferas de formação profissional, a universidade, as instituições religiosas e a socialização de gênero. $\mathrm{O}$ artigo, com base em uma perspectiva relacional, detecta entre as alunas um conflito entre o aprendizado secular e o religioso, demonstrando que as tomadas de posição acerca de assuntos polêmicos no âmbito da socialização religiosa passam a ser geridas por um conjunto de disposições híbridas de habitus. Tendo como referência os estudos de Setton (2002; 2002a; 2012), Knoblauch (2017) empreende uma análise exploratória sobre o uso do conceito de socialização em sociedades multiculturais e plurirreligiosas.

Os outros três artigos restantes — Peregrino (2011), Almeida (2014) e Garcia e Dominguez (2018) - , discursando a respeito da entrada dos jovens no mundo do trabalho, compreendem esse espaço como um agente socializador. Ou seja, o trabalho e a vida profissional operam como instâncias de transmissão de práticas, contribuindo para a constituição de universos identitários singulares. A passagem para o mundo profissional enseja mudanças e/ou rupturas com valores e comportamentos da juventude. Destaca-se o artigo de Almeida (2014), que faz uma leitura não unilateral do processo de aprendizado. Para ela, a identidade profissional conta com a articulação entre elementos subjetivos e objetivos da vida do jovem, ampliando a reflexão sobre os limites e os alcances da socialização profissional.

\section{Socialização política}

A última categoria de análise, socialização política, é composta de 16 artigos. Em sua totalidade, são resultados de pesquisas realizadas em universidades brasileiras. Sete deles fazem parte de um dossiê organizado em 2016 pela revista Educação e Sociedade, do Centro de Estudos Educação e Sociedade (CEDES).

É notável que um número expressivo de estudos sobre aspectos da socialização política tome esse processo como um aprendizado contínuo, que ocorre em muitos espaços (escoteiros, internet, disciplinas escolares, escola, militância cultural e partidária, entre outros), mas não o defina conceitualmente (MORENO; ALMEIDA, 2009; CAETANO, 2016; RODRIGUES et al., 2018). Apropriando-se das categorias básicas das experiências socializadoras, notadamente o tempo, o acúmulo de vivências, o 
aprendizado pela vivência e pelos estímulos de pares, entre outros aspectos, considera-se dispensável a discussão sobre a interdependência entre as esferas responsáveis pela transmissão de um saber fazer, um aprendizado genérico de apreensão de crenças (MORENO; ALMEIDA, 2009; FUKS; PEREIRA, 2011; LERNER, 2016), percursos e itinerários realizados nos ambientes familiares (SEIDL, 2009), na internet e em sua capacidade de construir novas identidades políticas (BAQUERO et al., 2016), sindicalismo (YON, 2016) etc. Destaca-se desse grupo o trabalho de Leal (2013), que se ocupa em compreender a socialização em uma instituição total, a academia militar, tal como Erving Goffman a definiu. Isto é, uma experiência totalizante, homogênea, uniforme e disciplinada, com a expectativa de construir identidades talhadas para o desempenho de atividades ascéticas.

Outro bloco de artigos, contudo, traz uma reflexão acerca da socialização de forma mais encorpada, com conceitos e definições que auxiliam e ampliam a análise. Ou seja, abordam a vivência política (OKADO et al., 2018), o engajamento partidário (BRENNER, 2018), a militância ideológica (LECLERCQ, 2016) como produto de estratégias de convívio nos ambientes familiares, entre outros espaços, como a internet, os movimentos musicais, o marketing político (GOMES; SETTON, 2016), entre outros, capazes de construir disposições de habitus político, uma identidade subjetivada no espaço público (CASTRO; GRISOLIA, 2016).

As referências que dão base às discussões sobre a interação sujeitos sociais e instituições não são diferentes daquelas já citadas - Peter Berger e Thomas Luckmann, François Dubet, Danilo Martuccelli, Bernard Lahire, Muriel Darmon e Maria da Graça Setton —, contudo não se observou diálogo interno entre os autores que discutem a socialização política. São trabalhos solos que poderiam estar mais conectados entre si a fim de explicitar o jogo múltiplo de aprendizados na vida contemporânea. Não só a família, os partidos, os movimentos sociais, a internet, as mídias em geral compõem o imaginário e as representações militantes. Mais válido seria interpretar esse campo investigativo como resultante de um fenômeno social total, tal como proposto por Setton (2012), ou seja, "uma ação social vivida por uma dinâmica processual, com base na reciprocidade das mensagens e bens simbólicos entre agências e agentes socializadores, que envolve simultaneamente todos os indivíduos com a tarefa de manter o contrato e o funcionamento do social" (SETTON, 2012, p. 33).

\section{Considerações finais}

O objetivo deste artigo foi realizar um levantamento das pesquisas ou discussões relativas ao conceito de socialização, a fim de compreender seus usos nos últimos 20 anos. Tendo apreço pela noção de socialização e acreditando no potencial analítico que ela encerra, analisaram-se 87 artigos que abordaram o tema enquanto processo educativo. Foi possível observar que a maioria das investigações possui caráter empírico e é de natureza qualitativa, contudo um número expressivo dedicou-se a trazer discussões de caráter ensaístico na busca de ampliar o escopo de autores (GRIGOROWITSCHS, 2008; 2010) e/ou percepções acerca do fenômeno da socialização contemporânea (SETTON, 2002; PAIS, 2007; LIMA; FAZZI, 2018; CHAVES, 2015). Destaca-se, ainda, a forte presença de autores estrangeiros na tarefa de problematizar o uso da categoria a partir dos anos 2000 (BARRERE; MARTUCCELLI, 2001; TEDESCO, 2002; PLAISANCE, 2004; MOLLO-BOUVIER, 2005; LAHIRE, 2008; 2015; PETITAT, 2011; HONNETH, 2013). No Brasil, esse movimento é bem mais tímido, ressalvando a contribuição contínua de Setton (2002; 2002a; 2005; 2009; 2011; 2013; 2015; 2018) em um esforço explícito de demarcar um campo de investigação. 
Embora grande parte dos trabalhos aqui analisados trate a socialização como uma somatória de experiências de aprendizado, portanto, uma continuidade entre socialização primária e secundária, tal como Berger e Luckmann (1983) as definiram, poucos apontam a existência de rupturas identitárias em função de novos ensinamentos (SETTON, 2005; LECLERCQ, 2016; KNOBLAUCH, 2017). É como se o olhar sobre os processos socializadores não sinalizasse lutas, conflitos ou a articulação entre práticas.

É possível verificar, seguindo as indicações de Lahire (2015), em seu alerta aos pesquisadores nos artigos aqui comentados, que entre as pesquisas em tela poucas conseguiram se apropriar de maneira concreta de tais experiências. Ou seja, segundo o autor, a noção de socialização não foi mobilizada como conceito científico. Para tal, elas deveriam constituir estudos de caso precisos. Para Lahire (2015), aqueles que se ocupam da noção deveriam fazer uso de quatro categorias: quadros (instituições); modalidades (maneiras e formas de agir); efeitos (disposições de agir); e tempo (momento de percurso individual). Os estudos deveriam, pois, localizar em um tempo e em um espaço, bem como descrever e analisar, mecanismos de socialização bem determinados. Tratar-se-ia de alcançar o nível das práticas e das disposições institucionais a que os sujeitos se submetem nas experiências de socialização.

Num movimento de síntese, é possível afirmar que nenhum dos artigos da categoria socialização profissional tem como programa a intenção anteriormente assinalada. Nas pesquisas do eixo socialização: família/escola, apenas Vianna (2005), Setton (2005), Quaresma (2015) e Leonardi (2017) se ocuparam de tais procedimentos.

É notável que os estudos da categoria infância e socialização de gênero possuem a preocupação em circunscrever de modo variado as diversas formas, lugares - espaçotemporais - de estratégias socializadoras, mesmo quando não têm como referência a obra de Bernard Lahire citada. Como já dito anteriormente, trata-se de um engajamento verificado entre os autores da sociologia da infância de reservar à noção de infância um novo lugar nas sociologias, isto é, uma compreensão que sinaliza um momento da vida em que se é capaz de produzir, reproduzir e/ou transformar as culturas, portanto, uma efetiva negociação entre os indivíduos.

No que se refere ao eixo socialização política, observa-se um movimento analítico próximo ao sinalizado por Lahire (2015). Verifica-se forte tendência em explicitar a interdependência entre as matrizes de socialização, entre elas família, escola, religião, internet etc., contudo de forma incipiente e sem diálogo interno entre autores. É comum, por outro lado, encontrar trabalhos que, ainda que usem fartamente o conceito de socialização enquanto processo, não usem referências da área (MORENO; ALMEIDA, 2009; 2009a; SEIDL, 2009; FUKS; PEREIRA, 2011; LERNER, 2016). Uma bibliografia de referência acerca da socialização política é encontrada, sobretudo, na literatura anglo-saxã, destacando-se os autores Lagroye (2003), Sears e Valentino (1997) e Berger e Luckmann (1983).

Para finalizar, cumpre lembrar que os campos de investigação sobre socialização profissional e família/ escola parecem ser aqueles mais tradicionais, pois apresentaram artigos que remontam aos anos 1990. Por outro lado, o eixo socialização política surgiu como um tema emergente. Nesse sentido, este artigo proporcionou registrar autores brasileiros que construíram uma trajetória em tópicos habituais do campo da educação e outros que debatem novos eixos socializadores.

Em síntese, o conjunto de artigos aqui analisados permite afirmar que, se o conceito de socialização, ou processo de socialização, serve como noção corrente nas pesquisas da sociologia da educação, ainda não se configura como um operador analítico tal como descrito por Lahire (2015), ou como proposto por Setton (2002, 2002a, 2005, 2009, 2011, 2012, 2013, 2015, 2018), em seus estudos. Logo, é possível dizer que esse campo de investigação ainda não se estabeleceu em território nacional. Não se crê, porém, que esse fato encerre um prejuízo para a área, mas sinaliza esforços diferenciados que poderiam ser somados a fim de maior aprofundamento. Ainda temos tempo para tal empreitada. 


\section{Notas}

1. Em março de 2019, foi realizada busca complementar, a fim de contemplar os textos publicados em 2018.

2. As revistas estrangeiras não foram consideradas.

3. Ver Tabela 1, ao final do texto.

4. Neste trabalho, de modo a não repetir continuamente a palavra artigo, fizemos uso de outras expressões semelhantes.

5. Vale salientar que, no total de 334 documentos levantados nos periódicos A1, não foram considerados os artigos que traziam a palavra socialização em compreensão próxima ao senso comum.

6. Ver Tabelas 2-7 ao final do texto.

7. É professor de Sociologia na École Normale Supérieure (ENS) de Lyon, França. De 2003 a 2010, foi diretor do GRS, na Universidade Lumière Lyon 2, grupo que se destaca por ser um dos mais conceituados, na Europa, na produção acadêmica acerca do tema socialização.

8. É professora da FE-USP, coordenadora do Grupo de Práticas de Socialização (GPS), desde 2003 indexado no Conselho Nacional de Desenvolvimento Científico e Tecnológico (CNPq).

9. Ainda que o escopo da discussão deste artigo seja o período de 1998 a 2018, decidiu-se anexar o texto citado, pois ele se revela ímpar, anunciando o que muito depois se tornou corrente. Da mesma forma, foram incluídos os textos de Lucia Afonso (1995) e Menga Lüdke (1996). Vale sinalizar que a escolha do período do estudo, de 1998 a 2018 , nos pareceu adequado, porque constituía um espaço de tempo significativo, além de revelar em termos nacionais e internacionais o ressurgimento do conceito de socialização em função da emergência das novas sociologias (Corcuff, 2001).

\section{Contribuição dos autores}

Problematização e Conceituação: Setton MGJ; Metodologia; Setton MGJ, Bozzetto A. Análise; Setton MGJ, Bozzetto A. Redação; Setton MGJ, Bozzetto A.

\section{Referências}

ABRAMOWICZ, A.; OLIVEIRA, F. A Sociologia da infância no Brasil: uma área em construção. Educação, Santa Maria, v. 35, n. 1, p. 39-52, jan./abr. 2010.

ABRANTES, P. De como escrevemos a vida e a vida se inscreve em nós: um estudo da socialização através da análise de autobiografias. Educ. Soc., Campinas, v. 35, n. 126, p. 111-127, jan./mar. 2014. https://doi.org/10.1590/S0101-73302014000100007

AFONSO, L. Gênero e processo de socialização em creches comunitárias. Cad. Pesq., São Paulo, n. 93, p. 12-21, maio 1995.

ALMEIDA, M. S. A transição da escola para o mundo do trabalho constituída em objecto de estudo: Uma abordagem teórico-metodológica. Cad. Cedes, Campinas, v. 34, n. 94, p. 385-400, set./dez., 2014. https://doi.org/10.1590/S0101-32622014000300007

BANDEIRA, G. A. Um currículo de masculinidades nos estádios de futebol. Revista Brasileira de Educação, v. 15, n. 44, p. 342-351, maio/ago. 2010. https://doi.org/10.1590/S1413-24782010000200010

BAQUERO, M.; BAQUERO, R. V. A.; MORAIS, J. A. Socialização política e internet na construção de uma cultura política juvenil no sul do Brasil. Educ. Soc., Campinas, v. 37, n. 137, p. 989-1008, dez. 2016. https://doi.org/10.1590/es0101-73302016166022 
BARBOSA, M. C. S. Culturas escolares, culturas de infância e culturas familiares: as socializações e a escolarização no entretecer destas culturas. Educ. Soc., Campinas, v. 28, n. 100, p. 1059-1083, out. 2007. https://doi.org/10.1590/S0101-73302007000300020

BARRERE, A.; MARTUCCELli, D.. A escola entre a agonia moral e a renovação ética. Educ. Soc., Campinas, v. 22, n. 76, p. 258-277, out. 2001. https://doi.org/10.1590/S0101-73302001000300014

BERGER, P. L.; LUCKMANN, T. A construção social da realidade. Petrópolis: Vozes, 1983.

BERTHELOT, J.-M. Pour un bilan de la sociologie de l'éducation. In: COLLOQUE DE TOULOUSE, 1983. Anais [...]. Toulouse, 1983.

BOURDIEU, P. Pierre Bourdieu avec Löic Wacquant: Réponses. Paris: Seuil, 1992.

BOURDIEU, P. Meditações Pascalianas. Oeiras, Portugal: Ed. Celta, 1998.

BRENNER, A. K. Do potencial à ação: o engajamento de jovens em partidos políticos. ProPosições, Campinas, v. 29, n. 1, p. 239-266, abr. 2018. https://doi.org/10.1590/1980-6248-2016-0120

BRITO, R. S. Intrincada trama de masculinidades e feminilidades: fracasso escolar e meninos. Cad. Pesqui., São Paulo, v. 36, n. 127, p. 129-149, abr. 2006. https://doi.org/10.1590/S0100-15742006000100006 CAETANO, P. A socialização política dos estudantes no plural. Educ. Soc., Campinas, v. 37, n. 137, p. 1045-1060, dez. 2016. https://doi.org/10.1590/es0101-73302016165913

CAMACHO, L. M. Y. As sutilezas das faces da violência nas práticas escolares de adolescentes. Educ Pesq., São Paulo, v. 27, n. 1, p. 123-140, jun. 2001. https://doi.org/10.1590/S1517-97022001000100009

CARVALHO, M. P.; SENKEVICS, A. S.; LOGES, T. A. O sucesso escolar de meninas de camadas populares: qual o papel da socialização familiar? Educ. Pesqui., São Paulo, v. 40, n. 3, p. 717-734, set. 2014. https://doi.org/10.1590/s1517-97022014091637

CARVALHO, M. P. Teses e dissertações sobre gênero e desempenho escolar no Brasil (1993 - 2007): um estado da arte. Pro-Posições, Campinas, v. 23, n. 1, p. 147-162, abr. 2012. https://doi.org/10.1590/ S0103-73072012000100010

CASTRO, L. R.; GRISOLIA, F. S. Subjetivação pública ou socialização política? Sobre as articulações entre o "político" e a infância. Educ. Soc., Campinas, v. 37, n. 137, p. 971-988, out./dez., 2016. https:// doi.org/10.1590/es0101-73302016167363

CHAVES, M. W. As relações entre a escola e o aluno: uma história em transformação. Educ. Real., Porto Alegre, v. 40, n. 4, p. 1149-1167, out./dez. 2015. https://doi.org/10.1590/2175-623645958

CHAVES, M. W. O papel da igreja na educação escolar masculina na década de 1950. Cad. Pesqui., São Paulo, v. 42, n. 146, p. 518-537, maio/ago. 2012. https://doi.org/10.1590/S0100-15742012000200011

CORCUFF, P. As novas sociologias: construções da realidade social. Bauru: Edusc, 2001.

CORREIA, L. O.; GIOVANETTI, M. A.G. C.; GOUVEA, M. C. S. Movimentos sociais e experiência geracional: a vivência da infância no Movimento dos Trabalhadores sem Terra. Educ. rev., Belo Horizonte, n. 46, p. 143-166, dez. 2007. https://doi.org/10.1590/S0102-46982007000200005 
CURY, C. R. J. Educação escolar e educação no lar: espaços de uma polêmica. Educ. Soc., Campinas, v. 27, n. 96, p. 667-688, out. 2006. https://doi.org/10.1590/S0101-73302006000300003

DAYRELL, J. A escola "faz" as juventudes? Reflexões em torno da socialização juvenil. Educ. Soc., Campinas, v. 28, n. 100, p. 1105-1128, out. 2007. https://doi.org/10.1590/S0101-73302007000300022

DAYRELL, J. O rap e o funk na socialização da juventude. Educ. Pesqui., São Paulo, v. 28, n. 1, p. 117 136, jan./jun. 2002. https://doi.org/10.1590/S1517-97022002000100009

DELORY-MOMBERGER, C. Formação e socialização: os ateliês biográficos de projeto. Educ. Pesqui., São Paulo, v. 32, n. 2, p. 359-371, ago. 2006. https://doi.org/10.1590/S1517-97022006000200011

DIAS DA SILVA, R. R.; PEREIRA, A. L. V. Políticas de constituição do conhecimento escolar na pesquisa educacional brasileira. Cad. Pesqui., São Paulo, v. 43, n. 150, p. 884-905, set./dez. 2013. https://doi. org/10.1590/S0100-15742013000300008

DUBAR, C. A construção de si pela atividade de trabalho: a socialização profissional. Cad. Pesqui., São Paulo, v. 42, n. 146, p. 351-367, ago. 2012. https://doi.org/10.1590/S0100-15742012000200003

DURKHEIM, É. Educação e Sociologia. São Paulo: Melhoramentos, 1978.

FONTENELLE, I. A. O mundo de Ronald McDonald: sobre a marca publicitária e a socialidade midiática. Educ. Pesqui., São Paulo, v. 28, n. 1, p. 137-149, jan./jun. 2002. https://doi.org/10.1590/ S1517-97022002000100010

FREITAS, M. N. C. Organização escolar e socialização profissional de professores iniciantes. Cad. Pesqui., São Paulo, n. 115, p. 155-172, mar. 2002. https://doi.org/10.1590/S0100-15742002000100006 FUKS, M.; PEREIRA, F. B. Informação e conceituação: a dimensão cognitiva da desigualdade política entre jovens de Belo Horizonte. Rev. Bras. Ci. Soc., São Paulo, v. 26, n. 76, p. 123-143, jun. 2011. https:// doi.org/10.1590/S0102-69092011000200007

GARCIA, E. G.; DOMINGUEZ, J. L. S. La incorporación de los académicos a la Universidad Veracruzana: socialización y estrategias de los agentes en las disciplinas. Rev. Bras. Educ., Rio de Janeiro, v. 23, 2018. https://doi.org/10.1590/s1413-24782018230059

GARIGLIO, J. Â.A experiência escolar e a socialização pré-profissional de professores de educação física. Educ. rev., Belo Horizonte, v. 31, n. 2, p. 229-251, jun. 2015. https://doi. org/10.1590/0102-4698134352

GOMES, C. A.; PEREIRA, M. M. A formação do professor em face das violências das/nas escolas. Cad. Pesqui., São Paulo, v. 39, n. 136, p. 201-224, abr. 2009. https://doi.org/10.1590/S0100-15742009000100010

GOMES, E. E.; SETTON, M. G. J. Marketing e Educação Política: um estudo sobre agentes, estratégias e interpretações da cultura. Educ. Real., Porto Alegre, v. 41, n. 3, p. 853-872, jul./set. 2016. https:// doi.org/10.1590/2175-623651728

GOMES, J. V. Socialização primária: tarefa familiar? Cad. Pesq., São Paulo, n. 91, p. 54-61, nov. 1994. GOMES, L. O. O cotidiano, as crianças, suas infâncias e a mídia: imagens concatenadas. Pro-Posições, Campinas, v. 19, n. 3, p. 175-193, set./dez. 2008. https://doi.org/10.1590/ 


\section{S0103-73072008000300009}

GRIGOROWITSCHS, T. Jogo, mimese e infância: o papel do jogar infantil nos processos de construção do self. Rev. Bras. Educ., Rio de Janeiro, v. 15, n. 44, p. 230-246, maio/ago. 2010. https://doi.org/10.1590/ S1413-24782010000200003

GRIGOROWITSCHS, T. O conceito "socialização" caiu em desuso? Uma análise dos processos de socialização na infância com base em Georg Simmel e George H. Mead. Educ. Soc., Campinas, v. 29, n. 102, p. 33-54, jan./abr. 2008. https://doi.org/10.1590/S0101-73302008000100003

HONNETH, A. O eu no nós: reconhecimento como força motriz de grupos. Sociologias, Porto Alegre, ano 15, n. 33, p. 56-80, mai./ago. 2013. https://doi.org/10.1590/S1517-45222013000200003

KNOBLAUCH, A. Religião, formação docente e socialização de gênero. Educ. Pesqui., São Paulo, v. 43, n. 3, p. 899-914, set. 2017. https://doi.org/10.1590/s1517-9702201707163363

LAGROYE, J. La politisation. Paris: Belin, 2003.

LAHIRE, B. A fabricação social dos indivíduos: quadros, modalidades, tempos e efeitos de socialização. Educ. Pesqui., São Paulo, v. 41, n. especial, p. 1393-1404, dez. 2015. https://doi.org/10.1590/ S1517-9702201508141651

LAHIRE, B. Esboço do programa científico de uma sociologia psicológica. Educ. Pesqui., São Paulo, v. 34, n. 2, p. 373-389, maio/ago. 2008. https://doi.org/10.1590/S1517-97022008000200011

LEAL, G. F. Socialização em uma instituição total: implicações da educação em uma academia militar. Educ. Soc., Campinas, v. 34, n. 123, p. 389-406, abr./jun. 2013. https://doi.org/10.1590/ S0101-73302013000200004

LECLERCQ, C. Nativos mas não cativos: socialização comunista desde o berço e produção de papeis militantes. Educ. Soc., Campinas, v. 37, n. 137, p. 955-970, out./dez. 2016. https://doi.org/10.1590/ es0101-73302016165996

LEONARDI, P. Associações católicas como instâncias socializadoras e de controle do tempo: o caso do Liceu e do Santuário Sagrado Coração de Jesus. Pro-Posições, Campinas, v. 28, n. 3, p. 83-111, set./ dez. 2017. https://doi.org/10.1590/1980-6248-2016-0095

LERNER, S. L. T. M. Entre o moderno e o autoritário, o liberal e o conservador: o projeto de socialização político-ideológico contido na disciplina Estudo de Problemas Brasileiros. Educ. Soc., Campinas, v. 37, n. 137, p. 1029-1044, out./dez., 2016. https://doi.org/10.1590/es0101-73302016166364

LIMA, J. A.; FAZZI, R. C. A subjetividade como reflexividade e pluralidade: notas sobre a centralidade do sujeito nos processos sociais. Sociologias, Porto Alegre, ano 20, n. 48, p. 246-270, mai./ago. 2018. https://doi.org/10.1590/15174522-020004814

LOPES, J. R. Antropologia, educação e condicionamentos culturais: pensando as mediações no processo de socialização escolar. Educar em Revista, Curitiba, v. 25, n. 33, p. 171-188, 2009. https:// doi.org/10.1590/S0104-40602009000100012

LÜDKE, M.; BOING, L. A. Caminhos da profissão e da profissionalidade docentes. Educ. Soc., 
Campinas, v. 25, n. 89, p. 1159-1180, set./dez. 2004. https://doi.org/10.1590/S0101-73302004000400005

LÜDKE, M. Sobre a socialização profissional de professores. Cad. Pesq., São Paulo, n. 99, p. 5-15, nov. 1996.

MARCHI, R. C. As teorias da socialização e o novo paradigma para os estudos sociais da infância.

Educação \& Realidade, Porto Alegre, v. 34, n. 1, p. 227-246, jan./abr. 2009.

MARTINS FILHO, A. J. Práticas de socialização entre adultos e crianças, e estas entre si, no interior da creche. Pro-Posições, Campinas, v. 19, n. 1, p. 97-114, abr. 2008. https://doi.org/10.1590/ S0103-73072008000100014

MOLLO-BOUVIER, S. Transformação dos modos de socialização das crianças: uma abordagem sociológica. Educ. Soc., Campinas, v. 26, n. 91, p. 391- 403, maio/ago. 2005. https://doi.org/10.1590/ S0101-73302005000200005

MORAIS, A. M.; NEVES, I. P.. Estudo do posicionamento dos alunos na sua relação com o sucesso escolar. Educ. Real., Porto Alegre, v. 38, n. 1, p. 293-318, jan./mar. 2013. https://doi.org/10.1590/ S2175-62362013000100016

MORENO, R. C.; ALMEIDA, A. M. F. Isso é política, meu! Socialização militante e institucionalização dos movimentos sociais. Pro-Posições, Campinas, v. 20, n. 2, p. 59-76, ago. 2009. https://doi.org/10.1590/ S0103-73072009000200005

MORENO, R. C.; ALMEIDA, A. M. F. O engajamento político dos jovens no movimento hiphop. Rev. Bras. Educ., Rio de Janeiro, v. 14, n. 40, p. 130-142, abr. 2009. https://doi.org/10.1590/ S1413-24782009000100011

MORIN-MESSABEL, C. Representações das categorias de sexo em crianças no contexto escolar. Cad. Pesqui., São Paulo, v. 46, n. 160, p. 526-546, jun. 2016. https://doi.org/10.1590/198053143624

MOTA, K. S. Aulas de português fora da escola: famílias imigrantes brasileiras, esforços de preservação da língua materna. Cad. Cedes, Campinas, v. 24, n. 63, p. 149-163, maio/ago. 2004. https://doi. org/10.1590/S0101-32622004000200003

MULLER, F. Socialização na escola: transições, aprendizagem e amizade na visão das crianças. Educ. rev., Curitiba, n. 32, p. 123-141, 2008. https://doi.org/10.1590/S0104-40602008000200010

OKADO, L. T. A.; RIBEIRO, E. A.; LAZARE, D. C. M.. Partidarismo, ciclos de vida e socialização política no Brasil. Pro-Posições, Campinas, v. 29, n. 1, p. 267-295, abr. 2018. https://doi. org/10.1590/1980-6248-2016-0063

PAIS, J. M.. Cotidiano e reflexividade. Educ. Soc., Campinas, v. 28, n. 98, p. 23-46, jan./abr. 2007. https://doi.org/10.1590/S0101-73302007000100003

PETITAT, A. Educação difusa e relação social. Educ. Real., Porto Alegre, v. 36, n. 2, p. 365-377, maio/ ago. 2011.

PEREGRINO, M. Juventude, trabalho e escola: elementos para análise de uma posição social fecunda. Cad. Cedes, Campinas, vol. 31, n. 84, p. 275-291, maio/ago. 2011. https://doi.org/10.1590/ 


\section{S0101-73302007000100003}

PLAISANCE, E. Para uma sociologia da pequena infância. Educ. Soc., Campinas, v. 25, n. 86, p. 221 241, abr. 2004. https://doi.org/10.1590/S0101-73302004000100011

POLLOCK, L. Educação e ensino cultural dos ingleses em casa de 1550 a 1800. Educ. Real., Porto Alegre, v. 35, n. 3, p. 17-35, set./dez., 2010.

PRAZERES, M. Empresa HD, aluno monitor: a Microsoft e a construção da crença nas tecnologias. Educ. Pesqui., São Paulo, v. 41, n. 2, p. 527-542, abr./jun. 2015. https://doi.org/10.1590/s1517-97022015041662

QUARESMA, M. L. Entre a fruição do presente e o investimento no futuro: práticas extracurriculares estudantis em colégios privados. Educ. rev., Belo Horizonte, v. 31, n. 3, p. 97-118, jul./set. 2015. https:// doi.org/10.1590/0102-4698129417

RODRIGUES, M.; MENEZES, I.; FERREIRA, P. D. Efeitos longitudinais da socialização política nos comportamentos de participação de jovens. Educ. Pesqui., São Paulo, v. 44, e175560, jul. 2018. https:// doi.org/10.1590/s1678-4634201844175560

ROMANELLI, G. A produção no campo das relações família e escola: algumas perspectivas contemporâneas. In: ROMANELLI, G.; NOGUEIRA, M. A.; ZAGO, N. (orgs.). Família \& escola: novas perspectivas de análise. Petrópolis: Vozes, 2013. (Ciências da Educação).

SANTOS, S. V. S. Socialização de gênero na educação infantil: continuidades e rupturas vivenciadas pelas crianças na família, na igreja e na escola. Educação, Santa Maria, v. 42, n. 3, p. 731-750, set./dez. 2017 https://doi.org/10.5902/1984644428325.

SEARS, D. O.; VALENTINO, N. A. Politics Matters: political events as catalysts for preadult socialization. American Political Science Review, v. 91, n. 1, p. 45-65, mar. 1997. http://doi.org/10.2307/2952258

SEIDL, E. Disposições a militar e lógica de investimentos militantes. Pro-Posições, Campinas, v. 20, n. 2, p. 21-39, ago. 2009. https://doi.org/10.1590/S0103-73072009000200003

SENKEVICS, A. S.; CARVALHO, Marília Pinto de. Casa, rua, escola: gênero e escolarização em setores populares urbanos. Cad. Pesqui., São Paulo, v. 45, n. 158, p. 944-968, out./dez. 2015. https://doi. org/10.1590/198053143364

SETTON, M. G. J. Socialização de habitus: um diálogo entre Norbert Elias e Pierre Bourdieu. Rev. Bras. Educ., Rio de Janeiro, v. 23, p. 1-23, out. 2018. https://doi.org/10.1590/s1413-24782018230072

SETTON, M. G. J. A escolha e o reconhecimento pela educação: o caso de Antônio. Educ. Pesqui., São Paulo, v. 41, n. especial, p. 1405-1418, dez. 2015. https://doi.org/10.1590/S1517-9702201508141720

SETTON, M. G, J. Marcel Mauss e Norbert Elias: notas para uma aproximação epistemológica. Educ. Soc., Campinas, v. 34, n. 122, p. 195-210, mar. 2013. https://doi.org/10.1590/S0101-73302013000100011

SETTON, M. G. J. Socialização e Cultura: ensaios teóricos. 2. ed. São Paulo: Annablume, 2012.

SETTON, M. G. J. Teorias da socialização: um estudo sobre as relações entre indivíduo e sociedade. Educ. Pesqui., São Paulo, v. 37, n. 4, p. 711-724, dez. 2011. https://doi.org/10.1590/S1517-97022011000400003 
SETTON, M. G. J.A socialização como fato social total: notas introdutórias sobre a teoria do habitus. Rev. Bras. Educ., Rio de Janeiro, v. 14, n. 41, p. 296-307, ago. 2009. https://doi.org/10.1590/ S1413-24782009000200008

SETTON, M. G. J. Um novo capital cultural: pré-disposições e disposições à cultura informal nos segmentos com baixa escolaridade. Educ. Soc., Campinas, v. 26, n. 90, p. 77-105, abr. 2005. https:// doi.org/10.1590/S0101-73302005000100004

SETTON, M. G. J. Família, escola e mídia: um campo com novas configurações. Educ. Pesqui., São Paulo, v. 28, n. 1, p. 107-116, jan./jun. 2002. https://doi.org/10.1590/S1517-97022002000100008

SETTON, M. G. J. A teoria do habitus em Pierre Bourdieu: uma leitura contemporânea. Rev. Bras. Educ., Rio de Janeiro, n. 20, p. 60-70, maio/ago. 2002a. https://doi.org/10.1590/S1413-24782002000200005

SILVA, V. Jovens de um rural brasileiro: socialização, educação e assistência. Cad. Cedes, Campinas, v. 22, n. 57, p. 97-115, ago. 2002. https://doi.org/10.1590/S0101-32622002000200007

SIROTA, R. Primeiro os amigos: os aniversários da infância, dar e receber. Educ. Soc., Campinas, vol. 26, n. 91, p. 535-562, maio/ago. 2005. https://doi.org/10.1590/S0101-73302005000200012

TEDESCO, J. C. Os fenômenos de segregação e exclusão social na sociedade do conhecimento. Cad. Pesqui., São Paulo, n. 117, p. 13-28, nov. 2002. https://doi.org/10.1590/S0100-15742002000300002

THIN, D. Famílias populares e instituição escolar: entre autonomia e heteronomia. Educ Pesq., São Paulo, v. 36, n. especial, p. 65-77, 2010. https://doi.org/10.1590/S1517-97022010000400006

THIN, D. Para uma análise das relações entre famílias populares e escola: confrontação entre lógicas socializadoras. Rev. Bras. Educ., Rio de Janeiro, v. 11, n. 32, p. 211-225, ago. 2006. https://doi. org/10.1590/S1413-24782006000200002

THIN, D. Quartiers populaires : l'école et les familles. Lyon: Presses Universitaires de Lyon, 1998. https://doi.org/10.4000/books.pul.12393

TOMIZAKI, K; CARVALHO-SILVA, Hamilton Harley de; SILVA, Maria Gilvania Valdivino. Socialização política e politização entre famílias do movimento dos trabalhadores sem teto. Educ. Soc., Campinas, v. 37, n. 137, p. 935-954, dez. 2016. https://doi.org/10.1590/es0101-73302016166488

TOMIZAKI, K. Transmitir e herdar: o estudo dos fenômenos educativos em uma perspectiva intergeracional. Educ. Soc., Campinas, Educ. Soc., Campinas, v. 31, n. 111, p. 327-346, abr.-jun. 2010. https://doi.org/10.1590/S0101-73302010000200003

VELOSO, G. M.; VEIGA, C. G.; PAIVA, M. A. Escola Nova em Montes Claros: apropriações e significados atribuídos à individualização e à socialização (1920-1930). Rev. Bras. Educ., Rio de Janeiro, v. 23, p. 1-24, out. 2018. https://doi.org/10.1590/s1413-24782018230054

VIANNA, M. J. B. As práticas socializadoras familiares como locus de constituição de disposições facilitadoras de longevidade escolar em meios populares. Educ. Soc., Campinas, v. 26, n. 90, p. $107-$ 125, jan./abr. 2005. https://doi.org/10.1590/S0101-73302005000100005

VINCENT, G. Actes de la Table Ronde de Lyon (4 et 5 de fevrier 1988) Groupe de Recherche sur 
la Socialisation - Analyse des modes de socialisation - confrontations et perspectives - Université Lumière Lyon 2. Cahiers de Recherche, n. esp., maio 1988.

WEISS, E. Más allá de la socialización y de la sociabilidad: jóvenes y bachillerato en México. Educ Pesq., São Paulo, v. 41, n. especial, p. 1257-1272, dez. 2015. https://doi.org/10.1590/S1517-9702201508144889

YON, K. Os efeitos da socialização política de um sindicalismo "apolítico": um estudo de caso. Educ. Soc., Campinas, v. 37, n. 137, p. 1061-1076, out./dez., 2016. https://doi.org/10.1590/es0101-73302016166645

\section{Sobre as Autoras}

Maria da Graça Jacintho Setton é professora titular em Sociologia da Educação da Faculdade de Educação da Universidade de São Paulo (USP). Graduada e mestre em Ciências Sociais pela Pontifícia Universidade Católica de São Paulo e doutora em Sociologia pela Faculdade de Filosofia, Letras e Ciências Humanas da USP. É coordenadora do Grupo Práticas de Socialização Contemporâneas desde 2003. Atua nas áreas de sociologia, sociologia da educação e sociologia da cultura, com ênfase em temas relativos aos processos educativos e socializadores, numa perspectiva institucional (escola, mídia, religião, família, organizações voluntárias, organizações não governamentais), e também na perspectiva individual.

Adriana Bozzetto é professora adjunta do curso de Música: Licenciatura da Universidade Federal do Pampa, campus Bagé. Bacharel em Música (Piano), mestre e doutora em Música: Educação Musical pelo Programa de Pós-Graduação em Música da Universidade Federal do Rio Grande do Sul. Pós-doutora em Educação na Faculdade de Educação da USP, com supervisão de Maria da Graça Jacintho Setton. É membro do Grupo Educação Musical e Cotidiano (UFRGS) e do Grupo Práticas de Socialização Contemporâneas (USP). Atua nas áreas de educação musical e sociologia da educação musical, dedicando-se aos temas das trajetórias profissionais de professores de piano, mídias e aprendizagem de música no cotidiano de crianças e jovens, projeto educativo de famílias e socialização musical.

Recebido: 26 Ago 2019

Aceito: 29 Nov 2019 
Tabela 1. Periódicos da área de educação: quadriênio 2013-2016.

\begin{tabular}{|c|c|c|}
\hline Periódicos & Instituições & $\begin{array}{l}\text { Número de } \\
\text { artigos }(n=87)\end{array}$ \\
\hline Educação \& Sociedade & $\begin{array}{l}\text { Centro de Estudos Educação e Sociedade (CEDES) da } \\
\text { Universidade Estadual de Campinas (Unicamp) }\end{array}$ & 23 \\
\hline Educação e Pesquisa & $\begin{array}{l}\text { Faculdade de Educação da Universidade de São Paulo } \\
\text { (USP) }\end{array}$ & 15 \\
\hline Cadernos de Pesquisa & Fundação Carlos Chagas & 11 \\
\hline Revista Brasileira de Educação & $\begin{array}{c}\text { Associação Nacional de Pós-Graduação e Pesquisa em } \\
\text { Educação (ANPEd) }\end{array}$ & 9 \\
\hline Pro-posições & Faculdade de Educação da Unicamp & 8 \\
\hline Educação e Realidade & $\begin{array}{l}\text { Faculdade de Educação da Universidade Federal do Rio } \\
\text { Grande do Sul (UFRGS) }\end{array}$ & 6 \\
\hline Cadernos CEDES & CEDES, Unicamp & 4 \\
\hline Educação em Revista & $\begin{array}{l}\text { Faculdade de Educação da Universidade Federal de } \\
\text { Minas Gerais (UFMG) }\end{array}$ & 3 \\
\hline Sociologias & Programa de Pós-Graduação em Sociologia da UFRGS & 3 \\
\hline Educar em Revista & Universidade Federal do Paraná (UFPR) & 2 \\
\hline Educação & Universidade Federal de Santa Maria (UFSM) & 2 \\
\hline Revista Brasileira de Ciências Sociais & $\begin{array}{c}\text { Associação Nacional de Pós-Graduação e Pesquisa em } \\
\text { Ciências Sociais (Anpocs) }\end{array}$ & 1 \\
\hline
\end{tabular}


Tabela 2. Socialização em tempos contemporâneos.

\begin{tabular}{|c|c|c|c|}
\hline Periódico & Ano & Autor & Título \\
\hline $\begin{array}{l}\text { Revista Brasileira de } \\
\text { Educação }\end{array}$ & $\begin{array}{l}2018 \\
\text { v. } 23\end{array}$ & $\begin{array}{l}\text { Geisa Magela Veloso, } \\
\text { Cyntia Greiva Veiga e } \\
\text { Maria Aparecida Paiva }\end{array}$ & $\begin{array}{l}\text { "Escola Nova em Montes Claros: } \\
\text { apropriações e significados atribuídos à } \\
\text { individualização e à socialização" }\end{array}$ \\
\hline \multirow{2}{*}{ Educação e Realidade } & $\begin{array}{l}2011 \\
\text { v. } 36 \\
\text { n. } 2\end{array}$ & André Petitat & "Educação difusa e relação social" \\
\hline & $\begin{array}{l}2015 \\
\text { v. } 40 \\
\text { n. } 4\end{array}$ & Miriam Chaves & $\begin{array}{l}\text { "As relações entre a escola e o aluno: uma } \\
\text { história em transformação" }\end{array}$ \\
\hline \multirow{2}{*}{ Educação \& Sociedade } & $\begin{array}{l}2001 \\
\text { v. } 22 \\
\text { n. } 76\end{array}$ & $\begin{array}{c}\text { Anne Barrere e Danilo } \\
\text { Martuccelli }\end{array}$ & $\begin{array}{c}\text { "A escola entre a agonia moral e a } \\
\text { renovação ética" }\end{array}$ \\
\hline & $\begin{array}{l}2007 \\
\text { v. } 28 \\
\text { n. } 98\end{array}$ & José Machado Pais & "Cotidiano e reflexividade" \\
\hline \multirow{2}{*}{ Sociologias } & $\begin{array}{l}2013 \\
\text { v. } 15 \\
\text { n. } 33\end{array}$ & Axel Honneth & $\begin{array}{c}\text { "O eu no nós: reconhecimento como força } \\
\text { motriz de grupos" }\end{array}$ \\
\hline & $\begin{array}{l}2018 \\
\text { v. } 20 \\
\text { n. } 48\end{array}$ & $\begin{array}{c}\text { Jair Araújo de Lima e Rita } \\
\text { de Cássia Fazzi }\end{array}$ & $\begin{array}{l}\text { "A subjetividade como reflexividade e } \\
\text { pluralidade: notas sobre a centralidade do } \\
\text { sujeito nos processos sociais" }\end{array}$ \\
\hline \multirow{2}{*}{ Cadernos de Pesquisa } & $\begin{array}{c}2002 \\
\text { n. } 117\end{array}$ & Juan Carlos Tedesco & $\begin{array}{l}\text { "Os fenômenos de segregação e exclusão } \\
\text { social na sociedade do conhecimento" }\end{array}$ \\
\hline & $\begin{array}{l}2013 \\
\text { v. } 43 \\
\text { n. } 150\end{array}$ & $\begin{array}{l}\text { Roberto Rafael Dias da } \\
\text { Silva e Anna Luiza Verdi } \\
\text { Pereira }\end{array}$ & $\begin{array}{l}\text { "Políticas de constituição do } \\
\text { conhecimento escolar na pesquisa } \\
\text { educacional brasileira" }\end{array}$ \\
\hline Educar em Revista & $\begin{array}{l}2009 \\
\text { v. } 25 \\
\text { n. } 33\end{array}$ & José Rogério Lopes & $\begin{array}{c}\text { "Antropologia, educação e } \\
\text { condicionamentos culturais: pensando as } \\
\text { mediações no processo de socialização } \\
\text { escolar" }\end{array}$ \\
\hline \multirow{3}{*}{ Educação e Pesquisa } & $\begin{array}{l}2002 \\
\text { v. } 28 \\
\text { n. } 1\end{array}$ & Isleide Arruda Fontenelle & $\begin{array}{c}\text { "O mundo de Ronald McDonald: sobre } \\
\text { a marca publicitária e a socialidade } \\
\text { midiática" }\end{array}$ \\
\hline & $\begin{array}{l}2002 \\
\text { v. } 28 \\
\text { n. } 1\end{array}$ & Juarez Dayrell & $\begin{array}{c}\text { "O rap e o funk na socialização da } \\
\text { juventude" }\end{array}$ \\
\hline & $\begin{array}{l}2015 \\
\text { v. } 41 \\
\text { n. } 2\end{array}$ & Michelle Prazeres & $\begin{array}{l}\text { "Empresa HD, aluno monitor: a Microsoft } \\
\text { e a construção da crença nas tecnologias" }\end{array}$ \\
\hline
\end{tabular}


Tabela 3. Socialização e aportes teóricos.

\begin{tabular}{|c|c|c|c|}
\hline Periódico & Ano & Autor & Título \\
\hline \multirow{4}{*}{$\begin{array}{l}\text { Revista Brasileira de } \\
\text { Educação }\end{array}$} & $\begin{array}{l}2002 \\
\text { n. } 20\end{array}$ & $\begin{array}{l}\text { Maria da Graça } \\
\text { Jacintho Setton }\end{array}$ & $\begin{array}{c}\text { "A teoria do habitus em Pierre Bourdieu: } \\
\text { uma leitura contemporânea" }\end{array}$ \\
\hline & $\begin{array}{l}2009 \\
\text { v. } 14 \\
\text { n. } 41\end{array}$ & $\begin{array}{l}\text { Maria da Graça } \\
\text { Jacintho Setton }\end{array}$ & $\begin{array}{l}\text { "A socialização como fato social total: notas } \\
\text { introdutórias sobre a teoria do habitus" }\end{array}$ \\
\hline & $\begin{array}{l}2010 \\
\text { v. } 15 \\
\text { n. } 44\end{array}$ & Tamara Grigorowitschs & $\begin{array}{l}\text { "Jogo, mimese e infância: o papel do jogar } \\
\text { infantil nos processos de construção do self" }\end{array}$ \\
\hline & $\begin{array}{l}2018 \\
\text { v. } 23\end{array}$ & $\begin{array}{l}\text { Maria da Graça } \\
\text { Jacintho Setton }\end{array}$ & $\begin{array}{l}\text { "Socialização de habitus: um diálogo entre } \\
\text { Norbert Elias e Pierre Bourdieu" }\end{array}$ \\
\hline \multirow{6}{*}{ Educação e Pesquisa } & $\begin{array}{l}2002 \\
\text { v. } 28 \\
\text { n. } 1\end{array}$ & $\begin{array}{l}\text { Maria da Graça } \\
\text { Jacintho Setton }\end{array}$ & $\begin{array}{c}\text { "Família, escola e mídia: um campo com } \\
\text { novas configurações" }\end{array}$ \\
\hline & $\begin{array}{l}2006 \\
\text { v. } 32 \\
\text { n. } 2\end{array}$ & $\begin{array}{l}\text { Christine } \\
\text { Delory-Momberger }\end{array}$ & $\begin{array}{c}\text { "Formação e socialização: os ateliês } \\
\text { biográficos de projeto" }\end{array}$ \\
\hline & $\begin{array}{l}2008 \\
\text { v. } 34 \\
\text { n. } 2\end{array}$ & Bernard Lahire & $\begin{array}{l}\text { "Esboço do programa científico de uma } \\
\text { sociologia psicológica" }\end{array}$ \\
\hline & $\begin{array}{l}2011 \\
\text { v. } 37 \\
\text { n. } 4\end{array}$ & $\begin{array}{l}\text { Maria da Graça } \\
\text { Jacintho Setton }\end{array}$ & $\begin{array}{l}\text { "Teorias da socialização: um estudo sobre as } \\
\text { relações entre indivíduo e sociedade" }\end{array}$ \\
\hline & $\begin{array}{l}2015 \\
\text { v. } 41 \\
\text { n. especial }\end{array}$ & Bernard Lahire & $\begin{array}{l}\text { "A fabricação social dos indivíduos: } \\
\text { quadros, modalidades, tempos e efeitos de } \\
\text { socialização" }\end{array}$ \\
\hline & $\begin{array}{l}2015 \\
\text { v. } 41 \\
\text { n. especial }\end{array}$ & $\begin{array}{l}\text { Maria da Graça } \\
\text { Jacintho Setton }\end{array}$ & $\begin{array}{l}\text { "A escolha e o reconhecimento pela } \\
\text { educação: o caso de Antônio" }\end{array}$ \\
\hline Educação e Realidade & $\begin{array}{l}2009 \\
\text { v. } 34 \\
\text { n. } 1\end{array}$ & Rita de Cássia Marchi & $\begin{array}{c}\text { "As teorias da socialização e o novo } \\
\text { paradigma para os estudos sociais da } \\
\text { infância" }\end{array}$ \\
\hline \multirow{3}{*}{ Educação \& Sociedade } & $\begin{array}{l}2008 \\
\text { v. } 29 \\
\text { n. } 102\end{array}$ & Tamara Grigorowitschs & $\begin{array}{l}\text { "O conceito ‘socialização' caiu em desuso? } \\
\text { Uma análise dos processos de socialização } \\
\text { na infância com base em Georg Simmel e } \\
\text { George H. Mead” }\end{array}$ \\
\hline & $\begin{array}{l}2013 \\
\text { v. } 34 \\
\text { n. } 122\end{array}$ & $\begin{array}{l}\text { Maria da Graça } \\
\text { Jacintho Setton }\end{array}$ & $\begin{array}{l}\text { "Marcel Mauss e Norbert Elias: notas para } \\
\text { uma aproximação epistemológica" }\end{array}$ \\
\hline & $\begin{array}{l}2014 \\
\text { v. } 35 \\
\text { n. } 126\end{array}$ & Pedro Abrantes & $\begin{array}{l}\text { "De como escrevemos a vida e a vida se } \\
\text { inscreve em nós: um estudo da socialização } \\
\text { através da análise de autobiografias" }\end{array}$ \\
\hline
\end{tabular}


Tabela 4. Socialização na família/escola.

\begin{tabular}{|c|c|c|c|}
\hline Periódico & Ano & Autor & Título \\
\hline Pro-Posições & $\begin{array}{l}2017 \\
\text { v. } 28 \\
\text { n. } 3\end{array}$ & Paula Leonardi & $\begin{array}{c}\text { "Associações católicas como instâncias socializadoras } \\
\text { e de controle do tempo: o caso do Liceu e do } \\
\text { Santuário Sagrado Coração de Jesus" }\end{array}$ \\
\hline \multirow{3}{*}{ Educação e Pesquisa } & $\begin{array}{l}2001 \\
\text { v. } 27 \\
\text { n. } 1\end{array}$ & Luiza Camacho & $\begin{array}{l}\text { "As sutilezas das faces da violência nas práticas } \\
\text { escolares de adolescentes" }\end{array}$ \\
\hline & $\begin{array}{l}2010 \\
\text { v. } 36 \\
\text { n. esp. }\end{array}$ & Daniel Thin & $\begin{array}{l}\text { "Famílias populares e instituição escolar: entre } \\
\text { autonomia e heteronomia" }\end{array}$ \\
\hline & $\begin{array}{c}2015 \\
\text { v. } 41 \\
\text { n. esp. }\end{array}$ & Eduardo Weiss & $\begin{array}{c}\text { "Más allá de la socialización y de la sociabilidad: } \\
\text { jóvenes y bachillerato en México" }\end{array}$ \\
\hline Educação em Revista & $\begin{array}{l}2015 \\
\text { v. } 31 \\
\text { n. } 3\end{array}$ & Maria Luísa Quaresma & $\begin{array}{l}\text { "Entre a fruição do presente e o investimento no } \\
\text { futuro: práticas extracurriculares estudantis em } \\
\text { colégios privados" }\end{array}$ \\
\hline \multirow{2}{*}{ Educação e Realidade } & $\begin{array}{l}2010 \\
\text { v. } 35 \\
\text { n. } 3\end{array}$ & Linda Pollock & $\begin{array}{l}\text { "Educação e ensino cultural dos ingleses em casa de } \\
\qquad 1550 \text { a } 1800 "\end{array}$ \\
\hline & $\begin{array}{l}2013 \\
\text { v. } 38 \\
\text { n. } 1\end{array}$ & $\begin{array}{l}\text { Ana Maria Morais e } \\
\text { Isabel Pestana Neves }\end{array}$ & $\begin{array}{l}\text { "Estudo do posicionamento dos alunos na sua relação } \\
\text { com o sucesso escolar" }\end{array}$ \\
\hline \multirow{6}{*}{ Educação \& Sociedade } & $\begin{array}{l}2005 \\
\text { v. } 26 \\
\text { n. } 90\end{array}$ & $\begin{array}{l}\text { Maria José Braga } \\
\text { Vianna }\end{array}$ & $\begin{array}{c}\text { "As práticas socializadoras familiares como locus } \\
\text { de constituição de disposições facilitadoras de } \\
\text { longevidade escolar em meios populares" }\end{array}$ \\
\hline & $\begin{array}{l}2005 \\
\text { v. } 26 \\
\text { n. } 91\end{array}$ & Régine Sirota & $\begin{array}{c}\text { "Primeiro os amigos: os aniversários da infância, dar } \\
\text { e receber" }\end{array}$ \\
\hline & $\begin{array}{l}2005 \\
\text { v. } 26 \\
\text { n. } 90\end{array}$ & $\begin{array}{l}\text { Maria da Graça } \\
\text { Jacintho Setton }\end{array}$ & $\begin{array}{c}\text { "Um novo capital cultural: pré-disposições e } \\
\text { disposições à cultura informal nos segmentos com } \\
\text { baixa escolaridade" }\end{array}$ \\
\hline & $\begin{array}{l}2006 \\
\text { v. } 27 \\
\text { n. } 96\end{array}$ & Carlos Jamil Cury & $\begin{array}{l}\text { "Educação escolar e educação no lar: espaços de uma } \\
\text { polêmica" }\end{array}$ \\
\hline & $\begin{array}{l}2007 \\
\text { v. } 28 \\
\text { n. } 100\end{array}$ & Juarez Dayrell & $\begin{array}{c}\text { "A escola 'faz' as juventudes? Reflexões em torno da } \\
\text { socialização juvenil” }\end{array}$ \\
\hline & $\begin{array}{l}2010 \\
\text { v. } 31 \\
\text { n. } 111\end{array}$ & Kimi Tomizaki & $\begin{array}{l}\text { "Transmitir e herdar: o estudo dos fenômenos } \\
\text { educativos em uma perspectiva intergeracional" }\end{array}$ \\
\hline $\begin{array}{l}\text { Revista Brasileira de } \\
\text { Educação }\end{array}$ & $\begin{array}{l}2006 \\
\text { v. } 11 \\
\text { n. } 32\end{array}$ & Daniel Thin & $\begin{array}{c}\text { "Para uma análise das relações entre famílias } \\
\text { populares e escola: confrontação entre lógicas } \\
\text { socializadoras" }\end{array}$ \\
\hline Cadernos de Pesquisa & $\begin{array}{l}1994 \\
\text { n. } 91\end{array}$ & Jerusa Vieira Gomes & "Socialização primária: tarefa familiar?" \\
\hline \multirow{2}{*}{ Cadernos CEDES } & $\begin{array}{l}2002 \\
\text { v. } 22 \\
\text { n. } 57\end{array}$ & Vanda Silva & $\begin{array}{l}\text { "Jovens de um rural brasileiro: socialização, educação } \\
\text { e assistência” }\end{array}$ \\
\hline & $\begin{array}{l}2004 \\
\text { v. } 24 \\
\text { n. } 63\end{array}$ & Kátia Santos Mota & $\begin{array}{l}\text { "Aulas de português fora da escola: famílias } \\
\text { imigrantes brasileiras, esforços de preservação da } \\
\text { língua materna" }\end{array}$ \\
\hline
\end{tabular}


Tabela 5. Infância e socialização de gênero.

\begin{tabular}{|c|c|c|c|}
\hline Periódico & Ano & Autor & Título \\
\hline \multirow{5}{*}{ Cadernos de Pesquisa } & $\begin{array}{l}1995 \\
\text { n. } 93\end{array}$ & Lúcia Afonso & $\begin{array}{c}\text { "Gênero e processo de socialização em creches } \\
\text { comunitárias" }\end{array}$ \\
\hline & $\begin{array}{l}2006 \\
\text { v. } 36 \\
\text { n. } 127\end{array}$ & $\begin{array}{l}\text { Rosemeire dos } \\
\text { Santos Brito }\end{array}$ & $\begin{array}{l}\text { "Intricada trama de masculinidades e } \\
\text { feminilidades: fracasso escolar de meninos" }\end{array}$ \\
\hline & $\begin{array}{l}2012 \\
\text { v. } 42 \\
\text { n. } 146\end{array}$ & $\begin{array}{l}\text { Miriam Waidenfeld } \\
\text { Chaves }\end{array}$ & $\begin{array}{l}\text { "O papel da Igreja na educação escolar } \\
\text { masculina na década de } 1950 "\end{array}$ \\
\hline & $\begin{array}{l}2015 \\
\text { v. } 45 \\
\text { n. } 158\end{array}$ & $\begin{array}{l}\text { Adriano Souza } \\
\text { Senkevics e Marilia } \\
\text { Pinto de Carvalho }\end{array}$ & $\begin{array}{c}\text { "Casa, rua, escola: gênero e escolarização em } \\
\text { setores populares urbanos" }\end{array}$ \\
\hline & $\begin{array}{l}2016 \\
\text { v. } 46 \\
\text { n. } 160\end{array}$ & $\begin{array}{l}\text { Christine Morin- } \\
\text { Messabel, Severine } \\
\text { Ferrière e Aurelie Lainé }\end{array}$ & $\begin{array}{l}\text { "Representações das categorias de sexo em } \\
\text { crianças no contexto escolar" }\end{array}$ \\
\hline Educação em Revista & $\begin{array}{l}2007 \\
\text { n. } 46\end{array}$ & $\begin{array}{l}\text { Luciana Correia, Maria } \\
\text { Amélia Giovanetti e } \\
\text { Maria Cristina Gouvea }\end{array}$ & $\begin{array}{c}\text { "Movimentos sociais e experiência geracional: } \\
\text { a vivência da infância no Movimento dos } \\
\text { Trabalhadores sem Terra" }\end{array}$ \\
\hline Educação e Pesquisa & $\begin{array}{l}2014 \\
\text { v. } 40 \\
\text { n. } 3\end{array}$ & $\begin{array}{l}\text { Marilia Carvalho, } \\
\text { Adriano Senkevics e } \\
\text { Tatiana Loges }\end{array}$ & $\begin{array}{l}\text { "O sucesso escolar de meninas de camadas } \\
\text { populares: qual o papel da socialização familiar?" }\end{array}$ \\
\hline \multirow{3}{*}{ Pro-Posições } & $\begin{array}{l}2008 \\
\text { v. } 19 \\
\text { n. } 1\end{array}$ & Altino Martins Filho & $\begin{array}{c}\text { "Práticas de socialização entre adultos e crianças, } \\
\text { e estas entre si, no interior da creche" }\end{array}$ \\
\hline & $\begin{array}{l}2008 \\
\text { v. } 19 \\
\text { n. } 3\end{array}$ & Lisandra Ogg Gomes & $\begin{array}{l}\text { "O cotidiano, as crianças, suas infâncias e a } \\
\text { mídia: imagens concatenadas" }\end{array}$ \\
\hline & $\begin{array}{l}2012 \\
\text { v. } 23 \\
\text { n. } 1\end{array}$ & Marília Carvalho & $\begin{array}{l}\text { "Teses e dissertações sobre gênero e desempenho } \\
\text { escolar no Brasil (1993-2007): um estado da arte" }\end{array}$ \\
\hline $\begin{array}{l}\text { Revista Brasileira de } \\
\text { Educação }\end{array}$ & $\begin{array}{l}2010 \\
\text { v. } 15 \\
\text { n. } 44\end{array}$ & Gustavo Bandeira & $\begin{array}{l}\text { "Um currículo de masculinidades nos estádios } \\
\text { de futebol" }\end{array}$ \\
\hline \multirow{2}{*}{ Educação } & $\begin{array}{l}2017 \\
\text { v. } 42 \\
\text { n. } 3\end{array}$ & Sandro Sales Santos & $\begin{array}{l}\text { "Socialização de gênero na educação infantil: } \\
\text { continuidades e rupturas vivenciadas pelas } \\
\text { crianças na família, na igreja e na escola" }\end{array}$ \\
\hline & $\begin{array}{l}2010 \\
\text { v. } 35 \\
\text { n. } 1\end{array}$ & $\begin{array}{l}\text { Anete Abramowicz e } \\
\text { Fabiana de Oliveira }\end{array}$ & $\begin{array}{c}\text { "A sociologia da infância no Brasil: uma área em } \\
\text { construção" }\end{array}$ \\
\hline \multirow{3}{*}{ Educação \& Sociedade } & $\begin{array}{l}2004 \\
\text { v. } 25 \\
\text { n. } 86\end{array}$ & Eric Plaisance & "Para uma sociologia da pequena infância" \\
\hline & $\begin{array}{l}2005 \\
\text { v. } 26 \\
\text { n. } 91\end{array}$ & Suzanne Mollo-Bouvier & $\begin{array}{l}\text { "Transformação dos modos de socialização das } \\
\text { crianças: uma abordagem sociológica" }\end{array}$ \\
\hline & $\begin{array}{l}2007 \\
\text { v. } 28 \\
\text { n. } 100\end{array}$ & $\begin{array}{l}\text { Maria Carmen Silveira } \\
\text { Barbosa }\end{array}$ & $\begin{array}{l}\text { "Culturas escolares, culturas de infância } \\
\text { e culturas familiares: as socializações e a } \\
\text { escolarização no entretecer destas culturas" }\end{array}$ \\
\hline Educar em Revista & $\begin{array}{l}2008 \\
\text { n. } 32\end{array}$ & Fernanda Müller & $\begin{array}{l}\text { "Socialização na escola: transições, aprendizagem } \\
\text { e amizade na visão das crianças" }\end{array}$ \\
\hline
\end{tabular}


Tabela 6. Socialização profissional.

\begin{tabular}{|c|c|c|c|}
\hline Periódico & Ano & Autor & Título \\
\hline \multirow{2}{*}{ Cadernos CEDES } & $\begin{array}{l}2011 \\
\text { v. } 31 \\
\text { n. } 84\end{array}$ & Mônica Peregrino & $\begin{array}{l}\text { "Juventude, trabalho e escola: elementos para } \\
\text { análise de uma posição social fecunda" }\end{array}$ \\
\hline & $\begin{array}{l}2014 \\
\text { v. } 34 \\
\text { n. } 94\end{array}$ & Maria Sidalina Almeida & $\begin{array}{l}\text { "A transição da escola para o mundo do } \\
\text { trabalho constituída em objecto de estudo - } \\
\text { uma abordagem teórico-metodológica" }\end{array}$ \\
\hline Educação e Pesquisa & $\begin{array}{l}2017 \\
\text { v. } 43 \\
\text { n. } 3\end{array}$ & Adriane Knoblauch & $\begin{array}{c}\text { "Religião, formação docente e socialização de } \\
\text { gênero" }\end{array}$ \\
\hline $\begin{array}{l}\text { Revista Brasileira de } \\
\text { Educação }\end{array}$ & $\begin{array}{l}2018 \\
\text { v. } 23\end{array}$ & $\begin{array}{l}\text { Eréndira García Garcia } \\
\text { e José Luis Suárez } \\
\text { Dominguez }\end{array}$ & $\begin{array}{l}\text { "La incorporación de los académicos a la } \\
\text { Universidad Veracruzana: socialización y } \\
\text { estrategias de los agentes en las disciplinas" }\end{array}$ \\
\hline Educação em Revista & $\begin{array}{l}2015 \\
\text { v. } 31 \\
\text { n. } 2\end{array}$ & José Angelo Gariglio & $\begin{array}{l}\text { "A experiência escolar e a socialização pré- } \\
\text { profissional de professores de educação física" }\end{array}$ \\
\hline \multirow{4}{*}{ Cadernos de Pesquisa } & $\begin{array}{l}1996 \\
\text { n. } 99\end{array}$ & Menga Lüdke & $\begin{array}{l}\text { "Sobre a socialização profissional de } \\
\text { professores" }\end{array}$ \\
\hline & $\begin{array}{c}2002 \\
\text { n. } 115\end{array}$ & $\begin{array}{l}\text { Maria Nivalda de } \\
\text { Carvalho Freitas }\end{array}$ & $\begin{array}{c}\text { "Organização escolar e socialização profissional } \\
\text { de professores iniciantes" }\end{array}$ \\
\hline & $\begin{array}{c}2009 \\
\text { v. } 39 \\
\text { n. } 136\end{array}$ & $\begin{array}{l}\text { Candido Alberto Gomes e } \\
\text { Marlene Monteiro Pereira }\end{array}$ & $\begin{array}{l}\text { "A formação do professor em face das } \\
\text { violências das/nas escolas" }\end{array}$ \\
\hline & $\begin{array}{l}2012 \\
\text { v. } 42 \\
\text { n. } 146\end{array}$ & Claude Dubar & $\begin{array}{l}\text { "A construção de si pela atividade de trabalho: a } \\
\text { socialização profissional" }\end{array}$ \\
\hline Educação \& Sociedade & $\begin{array}{l}2004 \\
\text { v. } 25 \\
\text { n. } 89\end{array}$ & $\begin{array}{l}\text { Menga Lüdke e Luiz } \\
\text { Alberto Boing }\end{array}$ & $\begin{array}{l}\text { "Caminhos da profissão e da profissionalidade } \\
\text { docentes" }\end{array}$ \\
\hline
\end{tabular}


Tabela 7. Socialização política.

\begin{tabular}{|c|c|c|c|}
\hline Periódico & Ano & Autor & Título \\
\hline \multirow{8}{*}{$\begin{array}{l}\text { Educação \& } \\
\text { Sociedade }\end{array}$} & $\begin{array}{c}2013 \\
\text { v. } 34 \\
\text { n. } 123 \\
\end{array}$ & Giuliana Franco Leal & $\begin{array}{l}\text { "Socialização em uma instituição total: } \\
\text { implicações da educação em uma academia } \\
\text { militar" }\end{array}$ \\
\hline & $\begin{array}{l}2016 \\
\text { v. } 37 \\
\text { n. } 137 \\
\end{array}$ & $\begin{array}{c}\text { Kimi Tomizaki, Hamilton Harley } \\
\text { de Carvalho Silva e Maria Gilvania } \\
\text { Valdivino Silva }\end{array}$ & $\begin{array}{l}\text { "Socialização política e politização entre } \\
\text { famílias do movimento dos trabalhadores sem } \\
\text { teto" }\end{array}$ \\
\hline & $\begin{array}{l}2016 \\
\text { v. } 37 \\
\text { n. } 137 \\
\end{array}$ & $\begin{array}{l}\text { Lucia Rabello de Castro e Felipe } \\
\text { Salvador Grisolia }\end{array}$ & $\begin{array}{c}\text { "Subjetivação pública ou socialização política? } \\
\text { Sobre as articulações entre o 'político’ e a } \\
\text { infância” }\end{array}$ \\
\hline & $\begin{array}{l}2016 \\
\text { v. } 37 \\
\text { n. } 137\end{array}$ & Karel Yon & $\begin{array}{l}\text { "Os efeitos da socialização política de um } \\
\text { sindicalismo 'apolítico': um estudo de caso" }\end{array}$ \\
\hline & $\begin{array}{l}2016 \\
\text { v. } 37 \\
\text { n. } 137\end{array}$ & $\begin{array}{l}\text { Marcello Baquero, Rute Angelo } \\
\text { Baquero e Jennifer Azambuja de } \\
\text { Morais }\end{array}$ & $\begin{array}{l}\text { "Socialização política e internet na construção } \\
\text { de uma cultura política juvenil no sul do Brasil" }\end{array}$ \\
\hline & $\begin{array}{l}2016 \\
\text { v. } 37 \\
\text { n. } 137\end{array}$ & $\begin{array}{c}\text { Samara Lima Tavares Mancebo } \\
\text { Lerner }\end{array}$ & $\begin{array}{c}\text { "Entre o moderno e o autoritário, o liberal e o } \\
\text { conservador: o projeto de socialização político- } \\
\text { ideológico contido na disciplina Estudos de } \\
\text { Problemas Brasileiros" }\end{array}$ \\
\hline & $\begin{array}{l}2016 \\
\text { v. } 37 \\
\text { n. } 137\end{array}$ & Catherine Leclercq & $\begin{array}{l}\text { "Nativos, mas não cativos: socialização } \\
\text { comunista desde o berço e produção de papeis } \\
\text { militantes" }\end{array}$ \\
\hline & $\begin{array}{l}2016 \\
\text { v. } 37 \\
\text { n. } 137\end{array}$ & Pedro Caetano & $\begin{array}{c}\text { "A socialização política dos estudantes no } \\
\text { plural" }\end{array}$ \\
\hline \multirow{4}{*}{ Pro-Posições } & $\begin{array}{l}2009 \\
\text { v. } 20 \\
\text { n. } 2 \\
\end{array}$ & Ernesto Seidl & $\begin{array}{c}\text { "Disposições a militar e lógica de investimentos } \\
\text { militantes" }\end{array}$ \\
\hline & $\begin{array}{l}2009 \\
\text { v. } 20 \\
\text { n. } 2 \\
\end{array}$ & $\begin{array}{l}\text { Rosangela Carrilo Moreno } \\
\text { e Ana Maria F. Almeida }\end{array}$ & $\begin{array}{l}\text { "Isso é política, meu! Socialização militante e } \\
\text { institucionalização dos movimentos sociais" }\end{array}$ \\
\hline & $\begin{array}{l}2018 \\
\text { v. } 29 \\
\text { n. } 1\end{array}$ & Ana Karina Brenner & $\begin{array}{c}\text { "Do potencial à ação: o engajamento de jovens } \\
\text { em partidos políticos" }\end{array}$ \\
\hline & $\begin{array}{l}2018 \\
\text { v. } 29 \\
\text { n. } 1 \\
\end{array}$ & $\begin{array}{l}\text { Lucas Toshiaki A. Okado, } \\
\text { Ednaldo Aparecido Ribeiro e } \\
\text { Danilo César M. Lazare }\end{array}$ & $\begin{array}{l}\text { "Partidarismo, ciclos de vida e socialização } \\
\text { política no Brasil" }\end{array}$ \\
\hline $\begin{array}{c}\text { Revista } \\
\text { Brasileira de } \\
\text { Ciências Sociais }\end{array}$ & $\begin{array}{l}2011 \\
\text { v. } 26 \\
\text { n. } 76\end{array}$ & $\begin{array}{c}\text { Mario Fuks e } \\
\text { Frederico Batista Pereira }\end{array}$ & $\begin{array}{l}\text { "Informação e conceituação: a dimensão } \\
\text { cognitiva da desigualdade política entre jovens } \\
\text { de Belo Horizonte" }\end{array}$ \\
\hline $\begin{array}{l}\text { Revista } \\
\text { Brasileira de } \\
\text { Educação }\end{array}$ & $\begin{array}{l}2009 \\
\text { v. } 14 \\
\text { n. } 40\end{array}$ & $\begin{array}{l}\text { Rosangela Carrilo Moreno } \\
\text { e Ana Maria F. Almeida }\end{array}$ & $\begin{array}{l}\text { "O engajamento político dos jovens no } \\
\text { movimento hip-hop" }\end{array}$ \\
\hline $\begin{array}{l}\text { Educação e } \\
\text { Realidade }\end{array}$ & $\begin{array}{l}2016 \\
\text { v. } 41 \\
\text { n. } 3\end{array}$ & $\begin{array}{l}\text { Elias Evangelista Gomes e } \\
\text { Maria da Graça Jacintho Setton }\end{array}$ & $\begin{array}{c}\text { "Marketing e educação política: um estudo } \\
\text { sobre agentes, estratégias e interpretações da } \\
\text { cultura" }\end{array}$ \\
\hline $\begin{array}{l}\text { Educação e } \\
\text { Pesquisa }\end{array}$ & $\begin{array}{l}2018 \\
\text { v. } 44\end{array}$ & $\begin{array}{l}\text { Mariana Rodrigues, Isabel Menezes } \\
\text { e Pedro Ferreira }\end{array}$ & $\begin{array}{l}\text { "Efeitos longitudinais da socialização política } \\
\text { nos comportamentos de participação de jovens" }\end{array}$ \\
\hline
\end{tabular}

